\title{
Uterine and ovarian leukaemic relapse during bone marrow remission in acute lymphoblastic leukaemia
}

\author{
B. CANTWELL \\ M.B., M.R.C.P. \\ D. CANTWELL \\ M.D., F.R.C.R. \\ J. J. FENNELLY \\ M.D., F.R.C.P.I. \\ Departments of Medical Oncology and Radiology, St. Vincent's Hospital, Elm Park, Dublin 4
}

\begin{abstract}
Summary
A patient with acute lymphoblastic leukaemia who developed ovarian and uterine leukaemic relapse while in bone marrow remission is described. Pelvic relapse is rarely reported during the clinical course of leukaemia in females. Pelvic ultrasonography, a noninvasive procedure, was of value as an aid in detecting pelvic relapse.

\section{Introduction}

The testis is an important site of extramedullary relapse in childhood acute lymphoblastic leukaemia (ALL) (Oakhill et al., 1980; Eden et al., 1978). It is for this reason that, possibly in part, the prognosis for girls is better than for boys in childhood ALL (Hardisty, Kay and Peto, 1978). Although leukaemic involvement of the ovary has been described in autopsy series (Hustu and Aur, 1978), reports of clinical ovarian involvement are not common. We wish to report the use of pelvic ultrasonography as an aid in detecting pelvic relapse in a patient with ALL in bone marrow remission.
\end{abstract}

\section{Case report}

A 15-year-old female presented with severe anaemia, thrombocytopaenia and a peripheral white cell count of $240 \times 10^{9} /$ litre. ALL was confirmed by bone marrow examination. Remission induction and maintenance was smoothly achieved using the Medical Research Council protocol U.K.A.L.L. VI. The patient remained in full haematological remission as judged by repeated bone marrow examinations. Fifteen months later she complained of mild lower abdominal premenstrual pain, but initially no clinical abnormalities were detected on abdominal or rectal examination. However, the pains persisted and a mass arising from the pelvis became palpable on physical examination. Pelvic ultrasonography displayed an enlarged uterus (Fig. 1). Laparotomy revealed an enlarged uterus measuring $11.5 \mathrm{~cm}$ laterally and $14 \mathrm{~cm}$ vertically. The fallopian tubes appeared grossly normal but both ovaries were enlarged. A biopsy of the uterine musculature and a wedge resection of the left ovary were examined histologically. Both showed extensive infiltration by poorly differentiated lymphocytes. Bone marrow examination showed continued marrow remission.

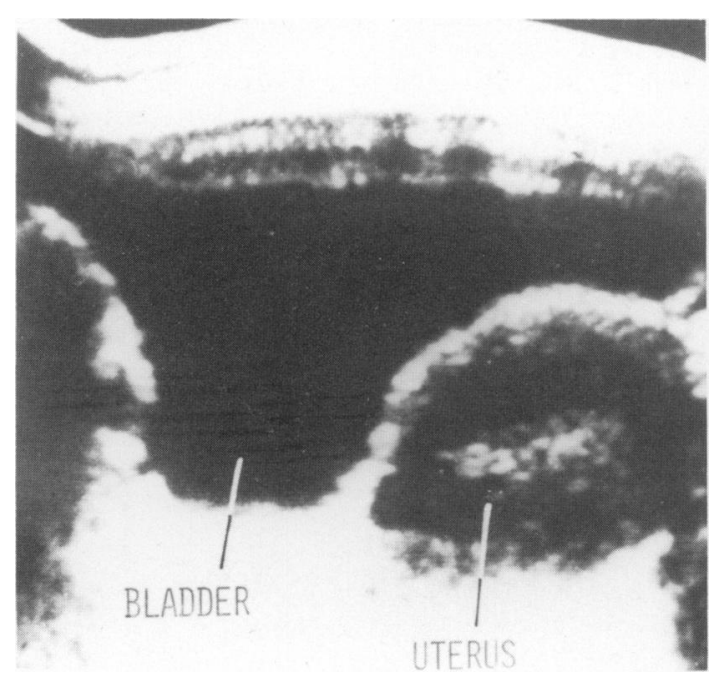

FIG. 1. Pelvic ultrasound scan, transverse view, showing enlarged uterus.

After laparotomy, the patient received pelvic irradiation and chemotherapy was changed to U.K. A.L.L. IV (intensive). However, 8 months from the diagnosis of pelvic relapse, central nervous system 
(CNS) relapse occurred. Bone marrow was in remission at the time of detection of CNS relapse. Subsequently, thyroid leukaemia involvement developed and death occurred 4 months later.

\section{Discussion}

This case illustrates pelvic (uterine and ovarian) relapse occurring in ALL in the presence of haematological remission, the patient later developing CNS and other extramedullary relapse. Although a rarely reported site of clinical relapse in childhood ALL, in a series of four cases of pelvic extramedullary leukaemic relapse, Cecalupo, Frankel and Sullivan (1979) describe one patient with both ovarian and uterine involvement. All four patients had been in continuous remission before pelvic relapse and subsequently two patients developed CNS relapse. Chu and colleagues (1981) describe a teenage girl with ALL who developed ovarian relapse, with a normal uterus, while in bone marrow remission. Obeid, Cotter and Sturdee (1977) report a 35-year-old female with a lower abdominal mass due to ovarian leukaemic involvement which was the first sign of relapse of acute lymphoblastic leukaemia.

Although pelvic relapse is uncommon in females with ALL it may become a more common clinical problem as increasing numbers of these patients are surviving longer using newer combinations of chemotherapy. In this case ultrasonography demonstrated pelvic abnormality, but was not performed before clinical detection of a palpable mass. Pelvic ultrasonography was performed on 15 girls with ALL in complete remission as part of a study which included invasive and non-invasive tests to detect occult extramedullary disease before discontinuation of chemotherapy (Mahoney et al., 1981). No ultrasonographic ovarian enlargement was found. However, since pelvic relapse involving sites other than the ovary may be difficult to diagnose early, pelvic ultrasonography, a safe and non-invasive procedure, needs further evaluation as a method to screen for pelvic relapse in acute lymphoblastic leukaemia.

\section{Acknowledgment}

We acknowledge the support of the Irish Cancer Society for B. Cantwell.

\section{References}

Cecalupo, A.J., Frankel, L.S. \& Sullivan, M.P. (1979) Pelvic and ovarian extramedullary leukemic relapse in young girls. Proceedings of the American Association for Cancer Research, 20, 365.

Chu, J-Y., Cradock, T.V., Danis, R.K. \& Tennant, N.E. (1981) Ovarian tumour as manifestation of relapse in acute lymphoblastic leukemia, Cancer (Philadelphia), 48, 377.

EDEN, O.B., HARDISTY, R.M., INNES, E.M., KAY, H.E.M. \& PETO, J. (1978) Testicular disease in acute lymphoblastic leukaemia in childhood. British Medical Journal, I, 344.

HARDISTY, R.M., KAY, H.E.M. \& PETO, J. (1978) Effects of varying radiation schedule, cyclophosphamide treatment, and duration of treatment in acute lymphoblastic leukaemia. Report to the Medical Research Council by the Working Party on Leukaemia in Childhood. British Medical Journal, 2, 787.

HUSTU, H.O. \& AUR, R.J.A. (1978) Extramedullary leukaemia. Clinics in Haematology, 7, 313.

Mahoney, D.H., Gonzales, E.T., Ferry, G.D., SANJAD, S.A., VAN NOORDEN, G.K. \& FERNBACH, D.J. (1981) Childhood acute leukemia: A search for occult extramedullary disease prior to discontinuation of chemotherapy. Cancer (Philadelphia), 48, 1964.

OAKhill, A., Mainwaring, D., Hill, F.G.H., Gornall, P., CudMORE, R.E., BANKS, A.J., BROCK, J.E.S., MARTIN, J. \& MANN, J.R. (1980) Management of leukaemic infiltration of the testis. Archives of Disease in Childhood, 55, 564.

OBEID, D., CotTER, P. \& STURDEE, D.W. (1979) Acute leukaemia relapse presenting as ovarian tumour. British Journal of Obstetrics and Gynaecology, 86, 578. 